Article (refereed) - postprint

Evans, Chris D.; Futter, Martyn N.; Moldan, Filip; Valinia, Salar; Frogbrook, Zoe; Kothawala, Dolly N.. 2017. Variability in organic carbon reactivity across lake residence time and trophic gradients. Nature Geoscience, 10 (11). 832-835. https://doi.org/10.1038/ngeo3051

(C) 2017 Macmillan Publishers Limited, part of Springer Nature

This version available http://nora.nerc.ac.uk/id/eprint/518436/

NERC has developed NORA to enable users to access research outputs wholly or partially funded by NERC. Copyright and other rights for material on this site are retained by the rights owners. Users should read the terms and conditions of use of this material at http://nora.nerc.ac.uk/policies.html\#access

This document is the author's final manuscript version of the journal article following the peer review process. Some differences between this and the publisher's version may remain. You are advised to consult the publisher's version if you wish to cite from this article.

https://www.nature.com/ 


\title{
Variability in organic carbon reactivity across lake residence time and trophic gradients
}

\author{
Chris D. Evans ${ }^{1}{ }^{*}$. Martyn N. Futter ${ }^{2}$, Filip Moldan ${ }^{3}$, Salar Valinia 4 , Zoe Frogbrook ${ }^{5}$, Dolly N. \\ Kothawala. \\ ${ }^{1}$ Centre for Ecology and Hydrology, Deiniol Road, Bangor, LL57 2UW, United Kingdom \\ ${ }^{2}$ Department of Aquatic Sciences and Assessment, Swedish University of Agricultural Sciences, Lennart \\ Hjälms Väg 9, 75007 Uppsala, Sweden \\ ${ }^{3}$ IVL Swedish Environmental Research Institute, P.O. Box 5302, 40014 Göteborg, Sweden
}

${ }^{4}$ Norwegian Institute for Water Research (NIVA), Gaustadalléen 21, 0349 Oslo, Norway; now at Swedish Environmental Protection Agency, SE-106 48 Stockholm, Sweden

${ }^{5}$ Scottish Water, 55 Buckstone Terrace, Edinburgh, EH10 6XH, United Kingdom

${ }^{6}$ Department of Ecology and Genetics/Limnology, Uppsala University, Norbyvägen 18D, 75236 Uppsala, Sweden

*cev@ceh.ac.uk

The transport of dissolved organic carbon from land to ocean is a large, dynamic component of the global carbon cycle. Inland waters are hotspots for organic matter turnover, via both biological and photochemical processes, and mediate carbon transfer between land, oceans and atmosphere. However, predicting dissolved organic carbon reactivity remains problematic. Here we present in situ dissolved organic carbon budget data from 82 predominantly European and North American water bodies with varying nutrient concentrations and water residence times ranging from one week to 700 years. We find that trophic status strongly regulates whether water bodies act as net dissolved organic carbon sources or sinks, and that rates of both dissolved organic carbon production and consumption can be predicted from water residence time. Our results suggest a dominant role of rapid light-driven removal in water bodies with a short water-residence time, whereas in water bodies with longer residence times, slower biotic production and consumption processes are dominant, and counterbalance one another. Eutrophication caused lakes to transition from sinks to sources of dissolved organic carbon. We conclude that rates and locations of dissolved organic carbon processing and associated $\mathrm{CO}_{2}$ emissions in inland waters may be misrepresented in global carbon budgets if temporal and spatial reactivity gradients are not accounted for.

Freshwater ecosystems are important conduits for carbon (C) transport ${ }^{1} ; \mathrm{CO}_{2}$ emissions associated with organic carbon $(\mathrm{OC})$ mineralisation, and $O C$ burial in lacustrine sediments, represent quantitatively important components of the global C cycle ${ }^{1-4}$. Dissolved organic carbon (DOC), which is the dominant $\mathrm{OC}$ fraction in most aquatic ecosystems, can be mineralised through microbial degradation and photochemical breakdown, removed via flocculation, and generated in situ via photosynthetic production or heterotrophic processing of particulate $O C^{4-6}$. Several recent studies have highlighted the importance of small, low water residence time (WRT) waterbodies as hotspots of aquatic $\mathrm{C}$ cycling ${ }^{6-9}$, however the relative importance of different processes in different aquatic systems, and thus their contribution to overall rates of freshwater OC processing, are not well quantified. The apparent turnover time of DOC, quantified as its half-life (T⿳亠丷厂二, i.e. time for concentrations to halve, which should be constant if exponential decay is occurring) varies over several orders of magnitude as a function of assessment method and study system; photodegradation experiments typically suggest $T \frac{1}{2}$ values of days to weeks ${ }^{10-13}$, with maximal rates observed in fresh samples from high-DOC headwaters. Biodegradation of labile compounds can be similarly rapid ${ }^{6}$, but studies based on typical 'humic' DOM suggest T1/2 values of months to years ${ }^{14-16}$. Lake and catchment budgets give $T 1 / 2$ estimates of $<1$ to $>100$ years ${ }^{17-18}$. Sharply differing indications of the relative 
importance of photochemical and biological processes have been obtained using different methods and/or in different ecosystems, e.g. it has been argued that photochemical processes account for $70-$ $95 \%$ of DOC processing in the shallow, unshaded waters of the Arctic ${ }^{5}$, whilst another study suggests that microbial processes account for $90 \%$ of organic matter consumption in lakes globally ${ }^{19}$. Several studies have concluded that aquatic $\mathrm{OC}$ reactivity decreases with transit time, due to selective removal of light-absorbing and bio-available compounds ${ }^{16,20}$.

Experimental assessments of DOC turnover necessarily involve a simplification of real-world conditions, for instance using specific compounds, excluding processes (e.g. photodegradation, photosynthesis, sediment-water interactions) or amplifying drivers (e.g. light, temperature) to generate measureable short-term responses. A key constraint of bioassay studies is that they are effectively closed reactors, often conducted in the absence of light, and typically excluding fresh inputs from primary production or terrestrial sources. Whole lake input-output budgets, on the other hand, expose a constantly cycling pool of natural DOC to ambient environmental conditions for a quantifiable time period. Although they present different challenges in disentangling the role of different drivers, we consider that whole lake budgets provide the most realistic indication of turnover rates in natural waters, and thus of the true role of freshwater ecosystems in the global $\mathrm{C}$ cycle. For 82 standing waterbodies with DOC budget data (68 lakes and 14 reservoirs from 12 countries, latitudinal range $14^{\circ} \mathrm{S}-61^{\circ} \mathrm{N}$, volumes $10^{4}-10^{13} \mathrm{~m}^{3}$ ) we calculated mean WRT, mean DOC output/input ratio (DOC out/DOC in) and T $1 / 2$ for waterbodies acting as DOC sinks (See Methods). WRT ranged from 0.01 to 690 years, and $\mathrm{DOC}_{\text {out }} / \mathrm{DOC}_{\text {in }}$ from 0.10 to 2.55 (see Supplementary Information).

\section{DOC input-output budgets}

Of the 82 waterbodies, 48 were annual net DOC sinks (defined as $>10 \%$ removal), of which 44 were nutrient-poor (oligotrophic), four moderately nutrient-enriched (mesotrophic) and none highly nutrient-enriched (eutrophic). The two largest lakes, Lake Superior and Lake Malawi, had by far the longest WRTs (170 and 690 years respectively) and greatest net DOC removal (> 80\%). The other 46 'sink' sites had $T 1 \frac{1}{2}$ values of 0.07 to 19 years. We observed a strong inverse relationship between $D O C_{\text {out }} / D O C_{\text {in }}$ and $\ln (W R T)$ across all DOC sink sites $\left(R^{2}=0.53, p<0.001 ;\right.$ Fig 1a). This relationship produced an even stronger correlation between DOC T1/2 and WRT, however this is attributable to the use of WRT to calculate T $1 / 2$ (see Supplementary Information). To examine variations in reactivity as a function of WRT we instead compared observed $D O C_{\text {out }} / D O C_{\text {in }}$ to values that would be predicted if DOC decay followed an average exponential decay function for the dataset (Fig 1a). Residuals (observed-predicted $\mathrm{DOC}_{\text {out }} / \mathrm{DOC}_{\text {in, }}$ Fig $1 \mathrm{c}$ ) were strongly and consistently negative at WRT $<1$ year (indicating higher-than-expected DOC removal) and positive (indicating lower-than-expected net DOC removal) in all but one waterbody with WRT $>2.5$ years. We found no significant correlation between the residuals of this relationship and any other available physical, hydrological or chemical property of the study sites, suggesting that WRT-related changes in DOC reactivity exert the dominant control on removal rates.

Fifteen waterbodies were net sources of DOC (defined as increase $>10 \%$, Fig 1b), of which 11 were mesotrophic or eutrophic, and 4 oligotrophic. These sites spanned a broad range of inflow and outflow DOC concentrations, from $<2$ to $>40 \mathrm{mg} \mathrm{l}^{-1}$ (Supplementary Table S4). Again we found a significant (but in this case positive) relationship between $D O C_{\text {out }} / D O C_{\text {in }}$ and $\ln (\mathrm{WRT})$ spanning all lake types $\left(\mathrm{R}^{2}\right.$ $=0.49, p=0.005$; Fig. 1c). As for DOC sink lakes, the log-linear relationship implies that net DOC production was not steady over time, but decreased with increasing WRT. 

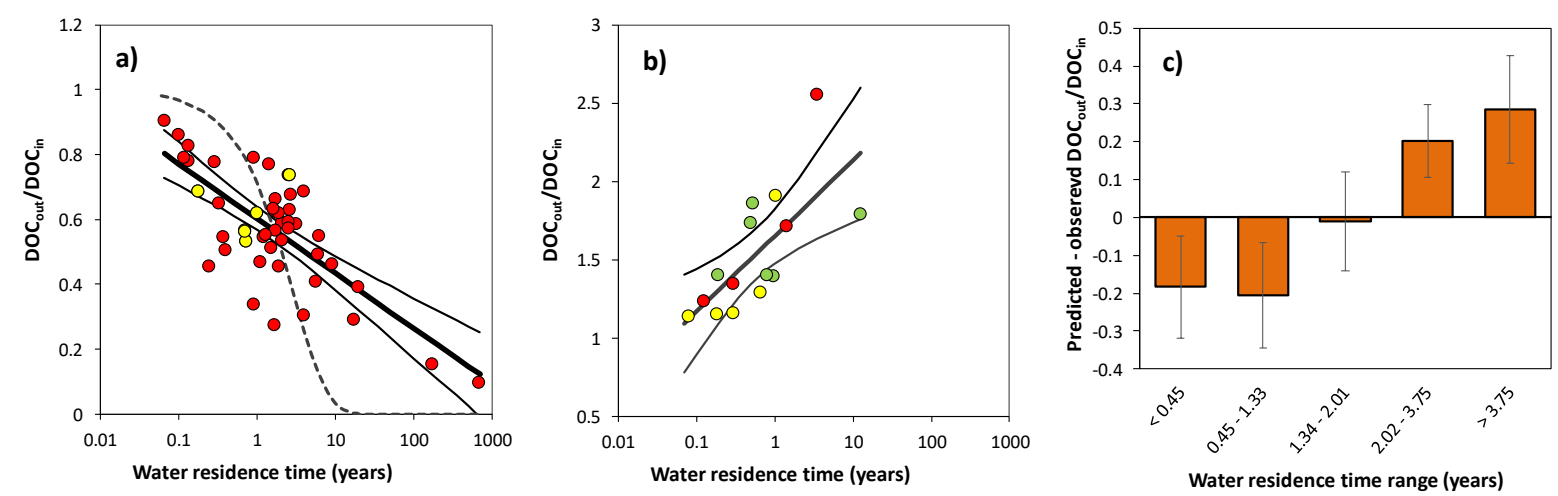

Figure 1. Relationships between $D O C_{\text {out }} / D O C_{\text {in }}$ and WRT for waterbodies acting as a) net DOC sinks and b) net DOC sources. Red, yellow and green circles represent oligotrophic, mesotrophic and eutrophic waterbodies respectively. Best fit (bold) and 95\% confidence intervals (narrow) lines were derived from a linear regression of $D O C_{\text {out }} / D O C_{\text {in }} v \ln (\mathrm{I}$ (WRT) for each set of waterbodies. The dashed line in (a) shows values of $D O C_{\text {out }} / D O C_{\text {in }}$ that would be predicted if all DOC sink sites followed an exponential decay curve with an average half-life, and c) shows divergence between observed and predicted $D O C_{\text {out }} / D O C_{\text {in }}$ obtained from this curve, for all DOC-sink sites binned into five equal-sized groups according to WRT.

The remaining 19 waterbodies were in approximate balance for DOC (change $< \pm 10 \%$ ). These sites varied in trophic status, however all but four had short WRTs ( $\leq 0.5$ years) and/or low DOC input fluxes $\left(<2 \mathrm{~g} \mathrm{C} \mathrm{m}^{-2} \mathrm{yr}^{-1}\right)$, and five had other lakes upstream (Table S4). We infer that net DOC change tends towards zero where opportunities for processing are limited (low inputs, low WRT); where preprocessing has occurred upstream (i.e. WRT of the individual waterbody underestimates true WRT); or where aquatic DOC production and terrigenous DOC consumption rates approach balance.

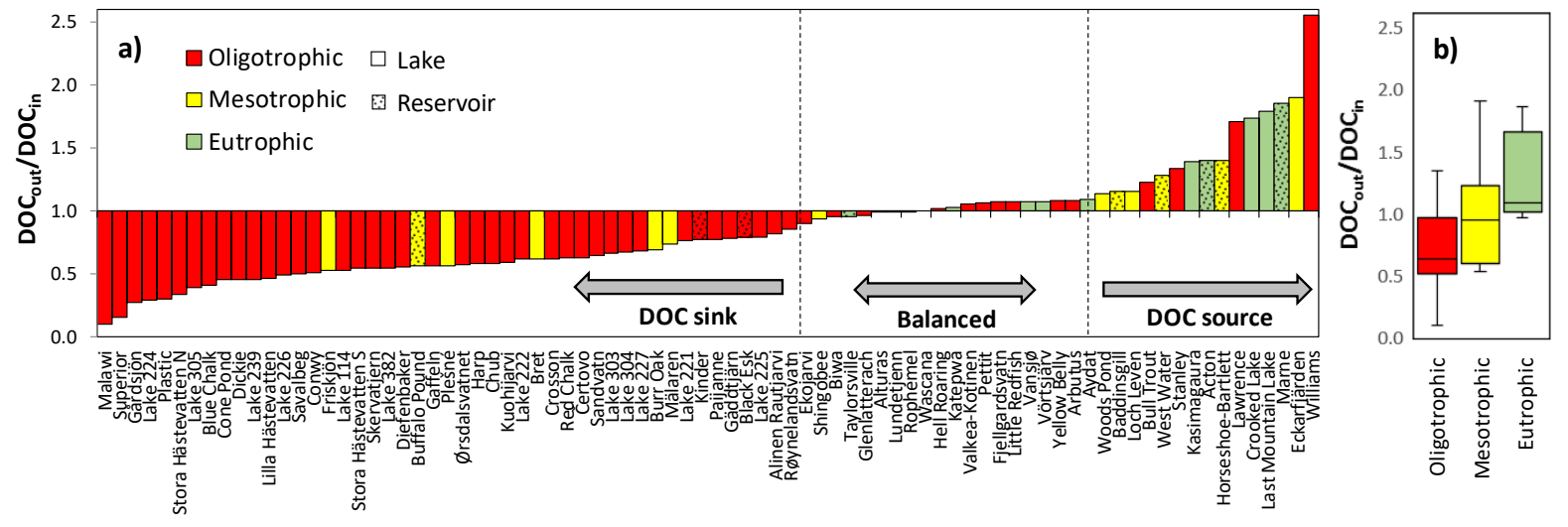

Figure 2. DOC input-output balance and trophic status of all waterbodies analysed: a) Lakes and reservoirs ranked from low to high $D O C_{o u t} / D O C_{i n}$, and classified by trophic status; b) Boxplot of median (line), quartile (box) and $10^{\text {th }} / 90^{\text {th }}$ percentile (whisker) values of $D O C_{\text {out }} / D O C_{\text {in }}$ by trophic status.

Our results highlight the role of lakes and reservoirs as active zones of OC cycling; $77 \%$ of studied sites were 'reactive', in the sense that they acted as either as net sources or net sinks of DOC. The direction of change was strongly influenced by nutrient status: $74 \%$ of 57 oligotrophic waterbodies were net sinks, whereas $76 \%$ of 25 meso-/eutrophic waterbodies were net sources (44\%) or balanced $(32 \%)$. Across the full dataset, mean $\mathrm{DOC}_{\text {out }} / \mathrm{DOC}_{\text {in }}$ was 0.70 (standard deviation \pm 0.31 ) in oligotrophic, 0.82 $( \pm 0.29)$ in mesotrophic, and $1.24( \pm 0.35)$ in eutrophic systems (Figure $2 b)$. Differences in $D O C_{\text {out }} / D C_{\text {in }}$ 
were highly significant between oligotrophic and eutrophic sites $(p<0.001)$, and between mesotrophic and eutrophic sites $(p=0.004)$, but non-significant between oligotrophic and mesotrophic sites $(p=0.23)$. Regardless of whether sites were net DOC sources or sinks, the overall rate and magnitude of DOC change was strongly influenced by WRT. For DOC sink sites this is consistent with declining reactivity over time as bio- and photo-labile fractions, and material susceptible to flocculation, are selectively removed. The non-linear relationship suggests that this does not occur evenly over time or space, with reactivity highest immediately following DOC transfer from land to water, and declining rapidly thereafter.

\section{The role of trophic status}

While data on net DOC source sites are constrained $(n=15)$ relative to sink sites $(n=48)$, there is a clear tendency towards net DOC production in nutrient-enriched waterbodies, and for declining production rates in longer-WRT systems. Our results are consistent with a previous input-output study of eutrophic ponds ${ }^{21}$ which showed DOC production coinciding with nutrient consumption during the growing season. We infer that autotrophic DOC production (e.g. via algal exudation or cell death, sloppy feeding by zooplankton, production by aquatic macrophytes) declines with time as available nutrients are incorporated into biomass and depleted. It is noteworthy that many of the balanced or net-DOC producing oligotrophic lakes had low catchment DOC inputs, a feature generally associated with higher inorganic nutrient levels ${ }^{22}$. Thus, a combination of low availability of terrestrial DOC to degrade, and somewhat higher nutrient levels, may favour net DOC production in these systems despite their low trophic status. It has also been suggested that supersaturation of natural waters with $\mathrm{CO}_{2}$ from terrigenous sources may stimulate primary production ${ }^{23}$. Given that photodegradation of organic matter liberates $\mathrm{CO}_{2}$ along with inorganic $\mathrm{N}$ and $\mathrm{P}$, the possibility exists of a direct mechanistic link between terrigenous DOC mineralisation (causing $\mathrm{CO}_{2}$ supersaturation) and aquatic DOC production.

\section{Implications for DOC processing rates}

For the subset of sites acting as net DOC sinks, we evaluated the extent to which processing rates occurring under ambient (light-exposed) conditions differed from those obtained under controlled (dark) conditions by comparing our in situ results to data from 221 dark incubation bioassays compiled previously ${ }^{16}$ to derive estimates of $O C$ decay rate, $k$ (proportional loss per year, related to half-life via $k=\ln (2) / T 1 / 2$ ). Divergence in fitted $k$ vs WRT for bioassay and input-output data (Fig. 3a) was greatest at short WRT ( 3 times higher at WRT $=0.02$ years), with $\mathrm{k}$ values converging at WRT $=1.4$ years, beyond which the incubation data suggest higher rates of DOC reactivity than the lake budget data (see Supplementary Information for details). These differences have important implications for the rate of DOC processing through drainage networks, and for the locations where processing occurs; the bioassay data suggest fairly steady but continued DOC removal over time ( $4 \%$ after 30 days, $36 \%$ after 1 year, 84\% after 10 years). The in situ data suggest much higher initial removal, but lower (net) removal over longer periods: $21 \%$ within 30 days, $40 \%$ after 1 year, and $57 \%$ after 10 years (Figure $3 \mathrm{~b}$ ). 

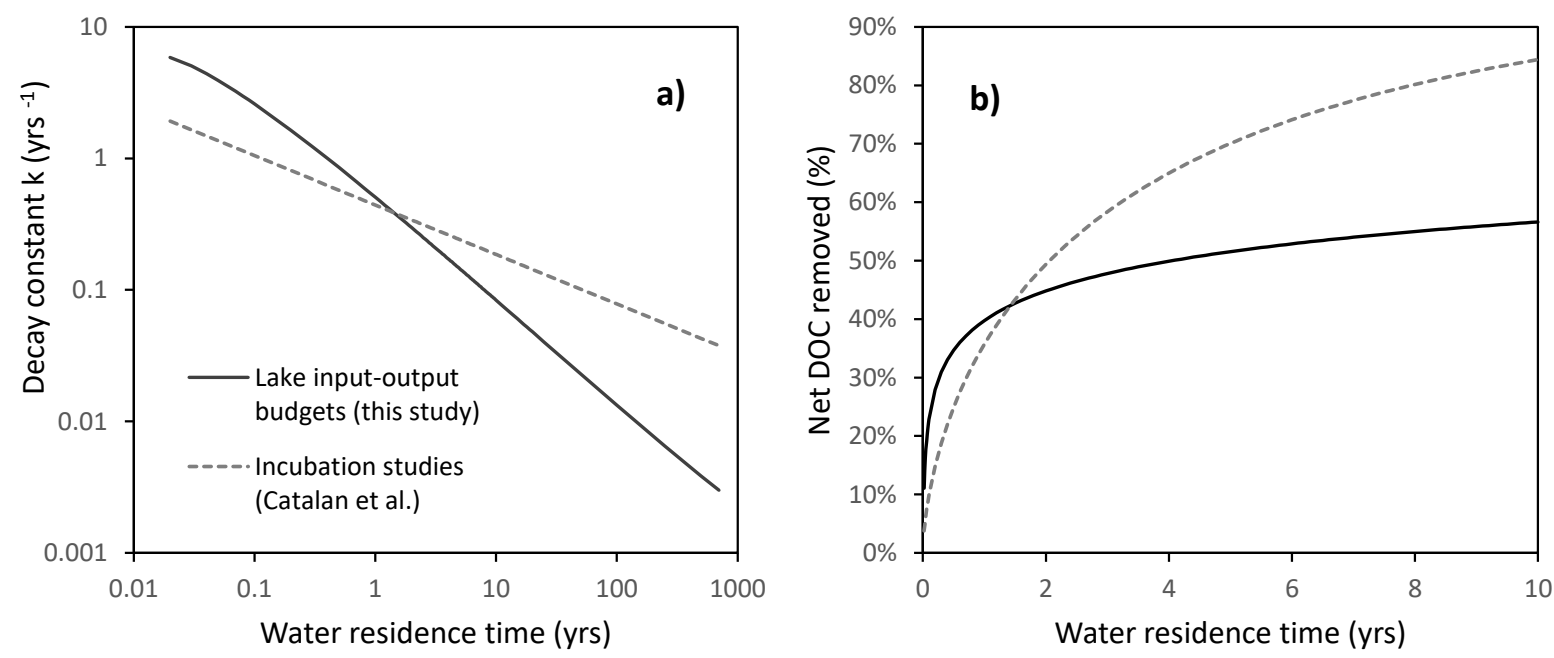

Figure 3. Contrasting relationships between $O C$ processing rates and water residence time obtained from in situ and laboratory incubation data: a) Fitted reaction rate (k) versus WRT based on lake input-output data from this study, and a previous relationship fitted to laboratory dark-incubation data by Catalan et al. $(2016)^{16}$. Relationships are truncated at WRT $=0.02$ years, the WRT at which DOC removal exceeds $10 \%$ according to our regression analysis (i.e. the threshold removal for sites to be defined as net DOC sinks) and at the maximum WRT in our lake dataset (690 years); b) Percentage removal of DOC versus WRT based on the two relationships shown in a).

The offset between field input-output data and dark bioassay data suggests a vital role of light-driven removal processes (e.g. photodegradation and flocculation, increased bioavailability of photomodified organic matter, and autotrophic production) ${ }^{24}$. Removal processes dominate in short-WRT systems, where photodegradability of freshly-exposed DOC is maximal, and where previous experimental studies have also suggested extremely high DOM reactivity ${ }^{10-13}$. This is particularly pronounced for headwaters draining peatlands, which are major global sources of surface water $\mathrm{DOC}^{26}$. Declining DOC reactivity, and convergence with bioassay-based $k$ estimates at higher WRT, can be interpreted as rapid initial loss/modification of the photo-labile DOC fraction, followed by a shift towards biological degradation of the residual DOC pool. Very low rates of net DOC removal at longer residence times, together with evidence of net DOC production in more nutrient-rich lakes, suggest that (under field conditions) in situ production increasingly counterbalances removal ${ }^{25}$. Large observed differences between light and dark DOC degradation rates have major implications not only for understanding mechanisms of DOC processing, but also for the locations where processing occurs. For a drainage system with a five year total WRT, our model (incorporating light-driven processes) suggests that $21 \%$ of all DOC removal occurs within the first week, $41 \%$ within a month, and $77 \%$ within a year. The equivalent dark-only figures are $5 \%, 12 \%$ and $51 \%$.

\section{Implications for aquatic carbon cycling}

Global $C$ budgets now incorporate freshwater $C$ transport, burial and emission ${ }^{1,4,9}$. A growing number of studies have identified the importance of headwater streams and small lakes ${ }^{4,7-9,21}$ but the magnitude and source of $\mathrm{CO}_{2}$ emissions from these systems remain uncertain ${ }^{2-3,9}$. Global lake area estimates range from 3 to 4 million $\mathrm{km}^{2}$, with small $\left(<1 \mathrm{~km}^{2}\right)$ water bodies comprising a highly uncertain (14-43\%) fraction of this total ${ }^{6-7}$. Raymond et al. ${ }^{9}$ estimate global stream area at 624,000 $\mathrm{km}^{2}$, half in first to third-order streams. They estimate that these account for $59 \%$ of stream $\mathrm{CO}_{2}$ emissions, but argue that such large emissions cannot be explained by degassing of $\mathrm{CO}_{2}$ exported from terrestrial systems alone. Whilst extrapolating from low-WRT lakes to streams is inherently uncertain, 
our analysis suggests that the very rapid, primarily photolytic, degradation and transformation of DOC immediately following land-water transfer could contribute significantly to this total flux. Conversely, long-WRT lakes may make a smaller contribution to DOC mineralisation than currently assumed. Nutrient-enrichment is an important confounding factor in the aquatic $C$ cycle, causing lakes to transition from DOC sinks to sources, but again processing rates appear maximal in low-WRT systems.

Overall, our study reinforces the view that low-WRT waterbodies are biogeochemical hotspots, and is among the first to empirically demonstrate the rapidity with which DOC processing rates (both production and consumption) change during the early period of exposure in the water column. This reactivity has arguably been overlooked in previous studies of larger lakes and/or dark-only processes. Our observations provide mechanistic underpinning for a number of other observations, including higher DOC concentrations ${ }^{27}$, rates of $\mathrm{CO}_{2}$ degassing ${ }^{9,28}$ and $\mathrm{C}^{\text {burial }}{ }^{29}$ in small versus large water bodies, and the 'chemostatic' stabilisation of DOC concentrations in larger drainage systems ${ }^{30}$. They suggest that extrapolation of process rates from large lakes to short-WRT systems may lead to underestimation of their biogeochemical significance, unless account is taken of the strongly non-linear relationship between DOC reactivity and WRT, and support a revised calculation of the contribution of small waterbodies to the global $\mathrm{C}$ budget.

\section{References}

1. Ciais, P et al. Climate Change 2013: The Physical Science Basis. Contribution of Working Group I to the Fifth Assessment Report of the Intergovernmental Panel on Climate Change. (2013).

2. Cole, J. J. et al. Plumbing the global carbon cycle: Integrating inland waters into the terrestrial carbon budget. Ecosystems 10, 172-185 (2007).

3. Battin, T. J. et al. The boundless carbon cycle. Nature Geosci. 2, 598-600 (2009).

4. Tranvik, L. J. et al. Lakes and reservoirs as regulators of carbon cycling and climate. Limnol. Oceanogr. 54, 2298-2314 (2009).

5. Cory, R. M., Ward, C. P., Crump, B. C. \& Kling, G. W. Sunlight controls water column processing of carbon in arctic fresh waters. Science 345 (2014).

6. Mineau, M.M. et al. Dissolved organic carbon uptake in streams: A review and assessment of reach-scale measurements. J. Geophys. Res. Biogeosci. 121, 2019-2029 (2016).

7. Benstead, J. P. \& Leigh, D. S. An expanded role for river networks. Nature Geosci. 5, 678-679 (2012).

8. Downing, J. A. et al. Global abundance and size distribution of streams and rivers. Inland Waters 2, 229-236 (2012).

9. Raymond, P. A. et al. Global carbon dioxide emissions from inland waters. Nature 503, 355-359 (2013).

10. Moody, C. S., Worrall, F., Evans, C. D. \& Jones, T. G. The rate of loss of dissolved organic carbon (DOC) through a catchment. J. Hydrol. 492, 139-150 (2013)

11. Molot, L.A., Hudson, J.J., Dillon, P.J. \& Miller, S.A. Effect of pH on photo-oxidation of dissolved organic carbon by hydroxyl radicals in a coloured, softwater stream. Aquat. Sci. 67, 189-195 (2005).

12. Köhler, S. J., Buffam, I., Jonsson, A. \& Bishop, K. Photochemical and microbial processing of stream and soilwater dissolved organic matter in a boreal forested catchment in northern Sweden. Aquat. Sci. 64, 269281 (2002).

13. Winter, A.R., Fish, T.A., Playle, R.C., Smith, D.S., \& Curtis, P.J. Photodegradation of natural organic matter from diverse freshwater sources. Aquat. Toxicol. 84, 215-222 (2007).

14. Wickland, K.P., Neff, J.C., Aiken, G.R. Dissolved organic carbon in Alaskan boreal forest: Sources, chemical characteristics, and biodegradability. Ecosystems, 10, 1323-1340 (2007). 
15. del Giorgio, P.A., \& Pace, M.L. Relative independence of dissolved organic carbon transport and processing in a large temperate river: The Hudson River as both pipe and reactor. Limnol. Oceanogr. 53, 185-197 (2008).

16. Catalán, N., Marcé, R., Kothawala, D. N. \& Tranvik, L. J. Organic carbon decomposition rates controlled by water retention time across inland waters. Nature Geosci. (2016).

17. Dillon, P.J. \& Molot, L.A. Dissolved organic and inorganic carbon mass balances in central Ontario lakes. Biogeochemistry 36, 29-42 (1997)

18. Weyhenmeyer, G.A. et al. Selective decay of terrestrial organic carbon during transport from land to sea. Global Change Biol. 18, 349-355 (2012).

19. Koehler, B., Landelius, T., Weyhenmeyer, G.A., Machida, N., Tranvik, L.J. Sunlight-induced carbon dioxide emissions from inland waters. Global Biogeochem. Cycl. 28, 696-711 (2014).

20. Obernoster, I. \& Benner, R. Competition between biological and photochemical processes in the mineralization of dissolved organic carbon. Limnol. Oceanogr. 49, 117-124 (2004).

21. Fairchild, G.W. \& Velinsky, D.J. Effects of small ponds on stream water chemistry. Lake Reservoir Manage. $22,321-330$ (2006)

22. Taylor, P. G. \& Townsend, A. R. Stoichiometric control of organic carbon-nitrate relationships from soils to the sea. Nature 464, 1178-1181 (2010).

23. Jansson, M., Karlsson, J., Jonsson, A. Carbon dioxide supersaturation promotes primary production in lakes. Ecol. Lett. 15, 527-532 (2012).

24. Moran, M. A. \& Zepp, R. G. Role of photoreactions in the formation of biologically labile compounds from dissolved organic matter. Limnol. Oceanogr. 42, 1307-1316 (1997).

25. Köhler, S.J., Kothawala, D., Futter, M.N., Liungman, O., Tranvik, L. In-lake processes offset increased terrestrial inputs of dissolved organic carbon carbon and color to lakes. PLOS ONE 8, e70598 (2013)

26. Aitkenhead, J.A. \& McDowell, W.H. Soil C:N as a predictor of annual riverine DOC flux at local and global scales. Global Biogeochem. Cycl. 14, 127-138 (2000).

27. Xenopoulos, M.A. et al. Regional comparisons of watershed determinants of dissolved organic carbon in temperate lakes from the Upper Great Lakes Region and selected regions globally. Limnol. Oceanogr. 48, 2321-2334 (2003).

28. Kelly, C.A. et al. Natural variability of carbon dioxide and net epilimnetic production in the surface waters of boreal lakes of different sizes. Limnol. Oceanogr. 46, 1054-1064 (2001).

29. Downing, J.A. Emerging global role of small lakes and ponds: little things mean a lot. Limnetica 29, 9-24 (2010)

30. Creed, I.F. et al. The river as a chemostat: Fresh perspectives on dissolved organic matter flowing down the river continuum. Can J. Fish. Aquat. Sci. 72, 1272-1285 (2015).

\section{Acknowledgements}

This work was undertaken with support received by CE as King Carl XVI Gustaf's 20th Visiting Professor in Environmental Science at the Swedish University of Agricultural Sciences, and from the UK Natural Environment Research Council Macronutrients Cycles Programme Grant No. NE/J011533/1. MF acknowledges the Nordforsk DOMQUA project (60501). We would like to thank Donald Edopka, Antti Räike, Linda May and Scottish Water for providing data included in the analysis.

\section{Author contributions}

CE conceived the study, undertook the initial data analysis and led the writing of the paper. MF and DK contributed to conceptual development and data analysis and wrote sections of the manuscript. FM, ZF and SV provided unpublished data, expert knowledge and ideas, and commented on the text. 


\section{Methods}

We collated data on the morphology and DOC input-output budgets of a range of waterbodies, including lakes and reservoirs, from a range of literature and several unpublished data sources. In the following method description we refer to 'lakes' for simplicity, but equivalent methods were used for reservoirs. Mean water residence time (WRT) in each lake was calculated as:

WRT (years) $=Q_{\text {out }} / V_{\text {lake }}$

Where $Q_{\text {out }}$ is the mean annual discharge from the waterbody $\left(\mathrm{m}^{3} \mathrm{yr}^{-1}\right)$ and $V_{\text {lake }}$ is lake volume $\left(\mathrm{m}^{3}\right)$. In many studies, $V_{\text {lake }}$ was not reported directly, but could be derived from reported values for lake area $\left(A_{\text {lake, }} \mathrm{m}^{2}\right)$ and mean depth $(Z, m)$. In some studies, WRT was reported directly, but one or other of $Q_{\text {out }}$ and $V_{\text {lake }}$ were not given, in which case the missing parameter was derived from the two reported parameters by rearranging (1). For all sites, areal mean discharge $\left(\mathrm{m} \mathrm{yr}^{-1}\right)$ was calculated as Qout divided by the area of the catchment, $A_{\text {catchment, }}$ which included the area of the lake. This was used to calculate the discharge into the lake $\left(Q_{i n}, \mathrm{~m}^{3} \mathrm{yr}^{-1}\right)$, if not already reported, by multiplying areal mean discharge by the terrestrial area of the catchment $\left(A_{\text {catchment }}-A_{\text {lake }}\right)$.

The calculation of DOC input and outputs varied according to the information provided in the study and the nature of the site. In the simplest case, for lakes dominated by a single large river input (i.e. one draining the majority of the lake catchment area) the mean concentration of DOC in this input was considered representative of all catchment inputs (i.e. the same mean DOC concentration was assumed for unmeasured lake inflows and direct seepage) and scaled up to the full terrestrial catchment area assuming a constant DOC flux per unit area. The total DOC input was then calculated as the mean inflow concentration ( $[D O C]_{\text {in }} \mathrm{g} \mathrm{m}^{-3}$ ) multiplied by $Q_{i n}$. For lakes with multiple sampled inflows $[D O C]_{\text {in }}$ was calculated by weighting the mean concentrations of each inflow according to either gauged water discharge for each inflow (if reported) or alternatively according to subcatchment area. Although DOC input to waterbodies can occur through direct precipitation to the water surface, most studies that measured this flux found that it only contributed a few percent of the total DOC input $^{31,32}$. Because few studies reported rainfall fluxed, we assumed a zero DOC input via this pathway in all studies. Estimates of DOC inputs from emergent macrophytes reported in a number of studies ${ }^{31-}$

${ }^{34}$ were also omitted, as these were considered to comprise part of the in-lake production flux.

In a small number of reported studies, input-output budgets have been constructed for lakes without surface water inflows, based on estimates of seepage inputs ${ }^{31,34-36}$ or landscape averaged input fluxes ${ }^{37,38}$. These studies were included in the analysis provided that the estimates were based on direct measurements, e.g. of nearby stream catchments or subsurface inflows. Studies incorporating modelled fluxes ${ }^{39-41}$ were omitted in order to avoid circularity. We also excluded short-term (e.g. summer-only) mass-balance studies where changes in internal lake DOC storage were large and uncertain relative to input and output fluxes during the period ${ }^{42-43}$, and used multi-year means (treated as single data points) where available. Changes in storage should be negligible for short-WRT systems, and although they could arise lakes with longer WRTs, any errors associated with this should be randomly distributed within the dataset. We were unable to incorporate direct precipitation inputs of DOC to the lake surface in our mass-balance studies, because this term was rarely reported in the source literature. Where reported it was usually a minor term overall, but exceptions are likely where lake:catchment ratios are high, or terrestrial inputs low. By omitting this term we effectively assumed that any DOC deposited on the lake surface was rapidly cycled, and thus did not contribute to measured output fluxes. 
In general, reservoirs were treated similarly to natural lake systems in the analysis. However since reservoirs typically exhibit larger fluctuations in volume than lakes, we sought to use or calculate mean values of WRT based on the mean volume of water held within the reservoir during the measurement period, rather than its maximum capacity. One reservoir in France ${ }^{44}$ was supplied via a diversion canal and in this case areal mean water and DOC fluxes were calculated relative to the 'effective' catchment area of the reservoir, which was calculated by multiplying the total area of the catchment by the ratio of measured discharge from the reservoir to total catchment discharge. In one study ${ }^{45}$, DOC inputoutput budgets were reported for a two-reservoir chain, therefore a single combined WRT was calculated for this system.

For all sites, we calculated the ratio of output to input fluxes, $D O C_{\text {out }} / D O C_{i n}$. Sites were considered to be acting as $D O C$ sinks if $D O C_{\text {out }} / D O C_{\text {in }}<0.9$, and as net sources if $D O C_{\text {out }} / D O C_{\text {in }}>1.1$. Sites where outputs fluxes were within $10 \%$ of inputs were considered to be in approximate balance. The use of a $10 \%$ threshold was practical rather than theoretical, but reflected i) potential errors associated with determination of DOC input and output fluxes, that could lead to sites being erroneously categorised as net sources or sinks if a lower threshold were applied; and ii) increasing instability in calculated DOC reaction rates as the difference between inputs and outputs fell below this threshold.

For systems acting as DOC sinks, we determined DOC 'half-life' (DOC T1/2) according to the equation:

DOC $T 1 / 2=\frac{\ln (2) \times W R T}{-\ln \left(\frac{D O C_{\text {out }}}{D O C_{\text {in }}}\right)}$

Where $\mathrm{DOC}_{\text {in }}$ and $\mathrm{DOC}_{\text {out }}$ are area-normalised DOC input and output fluxes (both expressed in $\mathrm{g} \mathrm{C} \mathrm{m}^{-2}$ $\mathrm{yr}^{-1}$ as a function of the total catchment area, including lake area), and DOC T1/2 and WRT are both expressed in years. The instantaneous decay rate, $k$, was estimated as $\ln (2) /(D O C T 1 / 2)$. To avoid the possibility of a spurious relationship ${ }^{46}$ resulting from WRT being on both sides of the equation, the relationship between $k$ and WRT was estimated as follows. As DOC ${ }_{\text {out }}$ DOC $\mathrm{C}_{\text {in }}$ and WRT are independent measurements, the relationship between DOC consumption and WRT was quantified by simple linear regression, by fitting the following equation to the range of observations:

$\left(\frac{D O C_{\text {out }}}{D O C_{\text {in }}}\right)=\mathrm{a}+\mathrm{b} \times \ln (W R T)$

Prediction intervals for DOC consumption ratios $\widehat{y_{0}} \pm t_{\text {Crit }} \times s e$ were estimated as:

s.e. $=s_{y x} \times \sqrt{1+\frac{1}{n}+\frac{\left(x_{0}-\bar{x}\right)^{2}}{S S_{x}}}$

Thus, the upper prediction interval for the ratio of $\mathrm{DOC}_{\mathrm{Out}} / \mathrm{DOC}_{\mathrm{In}}$ was estimated as:

$\mathrm{Cl}_{\text {Upper }}=\mathrm{a}+\mathrm{b} X \ln (\mathrm{WRT})+\mathrm{t}_{\text {crit }} \mathrm{X}$ s.e.

And the lower prediction interval was estimated as:

$C_{\text {Upper }}=a+b X \ln (W R T)-t_{\text {Crit }} X$ s.e.

DOC half-life was obtained by substituting (3) into (2), giving:

DOC $T 1 / 2=\frac{\ln (2) \times W R T}{-\ln (\mathrm{a}+\mathrm{b} \times \ln (W R T))}$

Finally, prediction intervals for $T \frac{1}{2}$ were obtained by substituting ( $5 a$ and $b$ ) into (6).

At all sites, in addition to DOC fluxes and WRT, we collated or derived data on catchment and lake surface area, lake volume, mean depth, areal mean discharge and total discharge (see Supplementary Tables). To classify sites according to trophic status we collated available data for a range of nutrient and productivity measures, comprising total phosphorus (TP), soluble reactive phosphorus (SRP), total nitrogen (TN), nitrate $\left(\mathrm{NO}_{3}{ }^{-}\right)$and chlorophyll-a (Chl-a) concentration. Data reported by the same studies used for DOC flux calculations were used where possible, but obtained from additional sources 
where necessary. The most commonly measured parameter, TP, was used to categorise sites into three broad trophic classes, based on threshold values given by Dodds ${ }^{47}$ : oligotrophic (TP $\leq 23 \mu \mathrm{g} \mathrm{I}^{-1}$ ), mesotrophic $\left(23<\mathrm{TP} \leq 48 \mathrm{\mu g} \mathrm{I}^{-1}\right)$ and eutrophic $\left(\mathrm{TP}>48 \mathrm{\mu g}^{-1}\right)$. Where TP was not reported, other measured data plus author site descriptions and aerial imagery (evidence of agriculture and human habitation within the catchment) were used to assign trophic status (see Supplementary Information for details).

In total, we were able to derive annual DOC input-output budgets for a total of 82 waterbodies (68 lakes and 14 reservoirs) on four continents. With one exception, all were located in the Northern Hemisphere, and most were from the cool temperate or boreal zones.

Data sources. All of the data compiled for the analyses presented in this study are available in the Supplementary Information. The majority of data derive from previously published studies (see reference lists). Data from a small number of unpublished studies, and any additional calculations used to derive the values presented in Tables S1 to S4 where these were not reported directly in the original publication (see footnotes in Supplementary Information) are available from the corresponding author on request.

\section{References}

31. Carpenter, J.W., Green, R.H. \& Paterson, C.G. A preliminary organic carbon budget for a small dystrophic lake in Maritime Canada. Hydrobiologia 106, 275-282 (1983).

32. Cremona, F. et al. Dynamic carbon budget of a large shallow lake assessed by a mass balance approach. Hydrobiologia 731, 109-123 (2014).

33. Sobek, S., Söderbäck, B., Karlsson, S., Andersson, E. \& Brunberg, A.K. A carbon budget of a small humic lake: An example of the importance of lakes for organic matter cycling in boreal catchments. Ambio 35, 469-475 (2006).

34. Einola, E. et al. Carbon pools and fluxes in a chain of five boreal lakes: A dry and wet year comparison. J. Geophys. Res. 116, G03009 (2011).

35. Wetzel, R.G., Rich, P.H., Miller, M.C. \& Allen, H.L. Metabolism of dissolved and particulate detrital carbon in a temperate hard-water lake. Mem. Inst. Ital. Idrobiol. 29, 185-243 (1972).

36. Stets, E.G., Striegl, R.G., Aiken, G.R., Rosenberry, D.O. \& Winter, T.C. Hydrologic support of carbon dioxide flux revealed by whole-lake carbon budgets. J. Geophys. Res. 114, G01008 (2009).

37. Curtis, P.J. \& Schindler, D.W. Hydrologic control of dissolved organic matter in low-order Precambrian Shield lakes. Biogeochemistry 36, 125-138 (1997).

38. Persson, G. \& Broberg, O. Nutrient concentrations in the acidified Lake Gårdsjon: The role of transport and retention of phosphorus, nitrogen and DOC in watershed and lake. Ecol. Bull. 37, 158-175 (1985).

39. Hanson, P.C. et al. Fate of allochthonous dissolved organic carbon in lakes: A quantitative approach. PLOS ONE 6, e21884 (2011)

40. Hanson, P.C., Buffam, I., Rusak, J.A., Stanley, E.H. \& Watras, C. Quantifying lake allochthonous organic carbon budgets using a simple equilibrium model. Limnol. Oceanogr. 59, 167-181 (2014).

41. Weissenberger, S. et al. Modeling the carbon dynamics of the La Grande hydroelectric complex in northern Quebec. Ecol. Model. 221, 610-620 (2010).

42. Cole, J.J., Caraco, N.F., Strayer, D.L., Ochs, C. \& Nolan, S. A detailed organic carbon budget as an ecosystem-scale calibration of bacterial respiration in an oligotrophic lake during midsummer. Limnol. Oceanogr. 34, 286-296 (1989) 
43. Åberg, J., Bergström, A. K., Algesten, G., Söderback, K., \& Jansson, M. A comparison of the carbon balances of a natural lake (L. Örträsket) and a hydroelectric reservoir (L. Skinnmuddselet) in northern Sweden. Water Res., 38, 531-538 (2004).

44. Garnier, J., Leporcq, B., Sanchez, N., \& Philippon, X. Biogeochemical mass-balances (C, N, P, Si) in three large reservoirs of the Seine Basin (France). Biogeochemistry, 47, 119-146 (1999).

45. Parks, S. J., \& Baker, L. A. Sources and transport of organic carbon in an Arizona river-reservoir system. Water Res., 31, 1751st-1759 (1997).

46. Pearson, K. Mathematical contributions to the theory of evolution - on a form of spurious correlation which may arise when indices are used in the measurement of organs. Proc. Royal Soc. London 60, 489-498 (1897).

47. Dodds, W.K. Eutrophication and trophic state in rivers and streams. Limnol. Oceanogr. 51, 671680 (2006). 